\title{
From laboratory to bedside: a case report of a concise and pragmatic approach on heart failure
}

\begin{abstract}
Heart failure is one of the most common and intensely studied diseases in the world. Nevertheless, it is considered a difficult condition to diagnose and manage.

This case report, starting from the description of a brief clinical case, aims to directly and concisely explain the most important steps, from laboratory to bedside, in the diagnosis and management of heart failure disease. Physicians can rely on some laboratory tests (e.g., natriuretic peptides) and instrumental exams to diagnose and manage the patients in everyday medical practice. Finally, this article highlights that a multidisciplinary team management can improve the clinical status and the quality of life, thus preventing hospital admission and reducing mortality in patients with heart failure.
\end{abstract}

Keywords: Heart failure; Natriuretic peptides; Laboratories; Hematology; General practice; Disease Management; Patient Care Team

Dal laboratorio al letto del paziente: un esempio reale di un approccio conciso e pragmatico all'insufficienza cardiaca

CMI 2017; 11(2): 95-102

https://doi.org/10.7175/cmi.v11i2.1301

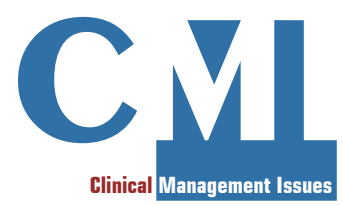

Case report
General practitioner; Azienda Sanitaria Locale Torino 2 (ASL TO2),

Torino, Piedmont, Italy

2 Trainee in general practice;

Azienda Sanitaria Locale

Cuneo 1 (ASL CN1),

Cuneo, Piedmont, Italy

\section{INTRODUCTION}

Heart failure (HF) is a chronic syndrome characterized by functional and structural cardiac abnormalities, which make the heart unable to maintain a flow rate adequate to the metabolic requirements of organs and tissues, if not at the cost of an increase of the filling pressures [1]. HF is a relevant problem to the healthcare worldwide and it is probably one of the most in-depth studied pathologies in clinical medicine. Its prevalence can reach 1-2\% in the Western world (rising to $10 \%$ or more among persons over 70 years of age) and its incidence can be estimated at 5-10 per 1000 persons per year [2]. Nevertheless, it is considered by physicians a difficult condition to diagnose and manage [3].

HF has very high morbidity and mortality, particularly in the elderly. Survival rate from diagnosis is almost $90 \%$ at 30 days, $80 \%$ at one year, and only $60 \%$ at five years [4].

Coronary artery disease (CAD) is the primary cause in up to $60-70 \%$ of cases of systolic HF [5]. Valvular heart disease and

Why we describe this case

Despite heart failure is a widespread and common disease, it is still problematic to diagnose and manage. General practitioners should always focus on the clinical history and the physical examination, looking for suggestive signs and symptoms, not forgetting to listen carefully to the patients, who sometimes do not report the most important changes in their behavior or they just rapidly mention them by chance
Corresponding author Andrea Pizzini andrea.pizzini09@gmail.com

Disclosure

The authors declare they have no competing financial interests concerning the topics of this article. 
hypertension are two significant risk factors for $\mathrm{HF}$, with a relative risk (RR) of 1.46 and 1.40 , respectively. Diabetes mellitus (DM) increases the risk of HF by directly causing cardiomyopathy and significantly contributing to CAD. Smoking, obesity, sedentary life, and a lower socioeconomic status are often neglected risk factors [6].

This article, starting from the description of a brief clinical case, aims to directly and concisely explain the most important steps, from laboratory to bedside, in the diagnosis and management of heart failure disease.

\section{CASE REPORT}

A 74-year-old woman of Caucasian origin goes to her general practitioner (GP) for the onset of dyspnea with moderate efforts for a few days. In her medical history, she has been suffering from essential hypertension (treated with $5 \mathrm{mg} /$ day of ramipril), chronic obstructive pulmonary disease (COPD) on stage B according to GOLD 2017 [7] (for which she was in therapy with salmeterol spray $50 \mu \mathrm{g}$ twice a day) and a modest dyslipidemia (kept in check just by diet).

As soon as she entered the medical office, after a quick greeting, she exclaimed with concern: «You know doctor, I'm old, it's true, but lately, while climbing the stairs, I feel breathless and in the evening my ankles are often swell». The GP, after having assessed that she was regularly taking all the previously prescribed medications, asked curiously: «In the past few days, did anything new happen to you?». «No, doctor. My life is so ordinary and flat. Among other things, before I forget... I need you to prescribe me diclofenac! My right hip has started again to ache for a few weeks and my neighbor gave me this drug... and it's really miraculous! Since I take it regularly every day, I feel no more pain in that area» she said.

The physical examination revealed that the blood pressure was $150 / 90 \mathrm{mmHg}$, the pulse was 105 beats per minute (bpm), the temperature was $36.8^{\circ} \mathrm{C}$, the respiratory rate was 23 breaths per minute, the oxygen saturation was $96 \%$ while she was breathing ambient air, her body mass index (BMI) was 25 (she reported a weight gain of $4 \mathrm{~kg}$ in the last few days), her skin was pale, and her peripheral pulses were normal. She had a distension of the jugular veins with ankle swelling. Her heart sounds were normal and rhythmic, with the presence of a third heart sound. At lung examination, bilateral basal crepitations were found, with mild wheezing spread. Her abdomen was soft and nontender, with palpable hepatomegaly $(2 \mathrm{~cm}$ below costal margin), and abdominojugular reflux sign was positive.

What should the clinician ask him/ berself or the patient?

1. What is the most likely diagnosis?

2. What strategy should be adopted to make a certain diagnosis?

3. How should this condition be managed?

4. Does this condition require hospitalization?

5. How should this condition be followed up?

\section{DISCUSSION}

\section{What is the most likely diagnosis? (Signs and symptoms)}

Taken together, these clinical features are suggestive for congestive heart failure condition, precipitated by the intake of non-steroidal anti-inflammatory drugs (NSAIDs).

The cardinal signs (i.e., pulmonary crepitations and/or peripheral edema) and symptoms (i.e., dyspnea) of heart failure are not specific and must be evaluated in light of the patient's history, the physical examination, and the findings of additional tests $[8,9]$. Other signs (e.g., enlarged heart, jugular vein distention, and a third heart sound) and symptoms (e.g., paroxysmal nocturnal dyspnea and orthopnea) have a diagnostic specificity ranging from $70 \%$ to $90 \%$, but a low sensitivity, ranging from $11 \%$ to $55 \%$ [10].

The presence of COPD in the patient's clinical history may be an important confounding factor in the differential diagnosis. However, the onset of peripheral edema, the rapid worsening of dyspnea, the pharmacological anamnesis, and the absence of fever and sputum make the hypotheses of worsening of the obstructive disease or bronchitis exacerbation less likely. One of the GP's tasks is to keep hypertensive patients under control avoiding organ complications, but this is sometimes hampered by the poor 
compliance of some patients in taking therapy and undergoing examinations.

Taking into account these considerations, a targeted medical history is of the utmost importance, keeping in mind that what can be useful for a physician may not always coincide with what the patient believes it is important to tell.

Hence, it's essential to remember some questions to ask about, such as [11]:

- How far can she walk before being out of breath?

- How many pillows does she use for sleeping?

- Does she wake up at night due to the feeling of breathlessness?

- Had she recently got chest pain?

- Did she recently take on her own initiative any drug that might exacerbate heart failure (such as steroids or NSAIDs)?

\section{What strategy should be adopted to make a certain diagnosis? (Essential initial investigations)}

The GP prescribed natriuretic peptides, electrocardiogram, chest radiography, transthoracic echocardiography, and some blood tests.

Natriuretic peptides (NPs) are a group of neurohormones that play an important role in fluid homeostasis [12]. Their plasma concentration is useful as early diagnostic test, particularly in non-acute setting, when echocardiography is not immediately accessible (Figure 1). Patients with normal NP concentration are unlikely to have HF [13], and they can avoid echocardiography. In fact, the B-type natriuretic peptide cut-off level of $35 \mathrm{pg} / \mathrm{ml}$ has a negative predictive value of $93 \%$ [14]. However, in this case the doctor decided to request a transthoracic echocardiography immediately, due to the strong suspicion of $\mathrm{HF}$ and in order to shorten the waiting times for the execution of this exam.

Even if the use of serial measurements of natriuretic peptides can be helpful in some specific cases in guiding therapeutic decisions, indicating the need to intensify the pharmacological treatment [15], this approach should not be recommended [8].

Electrocardiogram (ECG) is inexpensive, can be obtained immediately, and provides useful information about heart rhythm and electrical conduction. It may also show evidence of left ventricular hypertrophy or previous infarct. A normal electrocardiogram

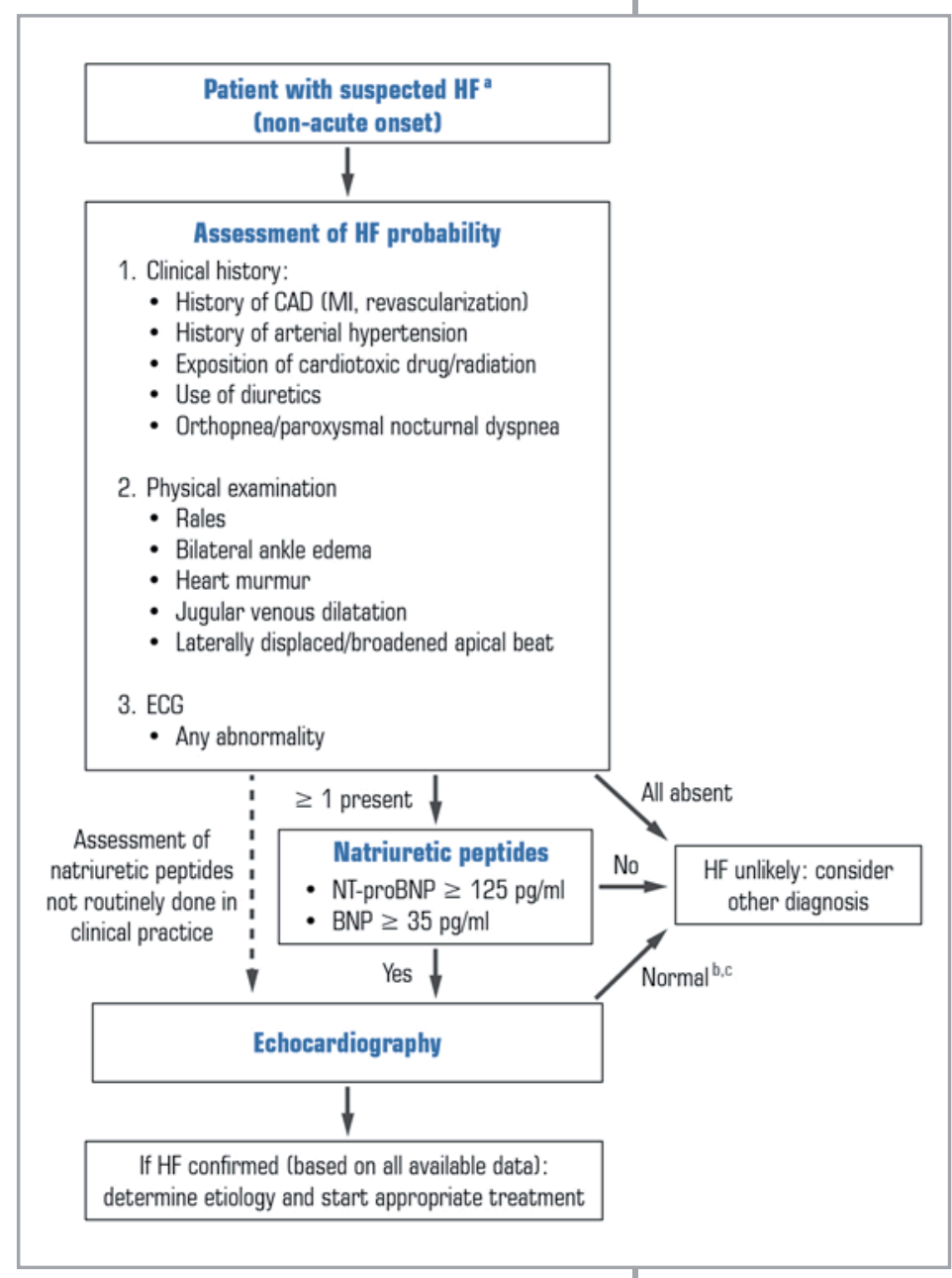

has a $90 \%$ negative predictive value for $\mathrm{ex}^{-}$ cluding systolic heart failure [16].

Chest radiography is useful to detect features suggestive for heart failure (such as pleural effusions and pulmonary edema) and to rule out other causes of breathlessness, like malignancies or infections [17].

Transthoracic echocardiography (TTE) allows the confirmation of the diagnosis, provides information on valvular and myocardial structure, and may detect other important features, such as myocardial diastolic and/or systolic function of right and/or left ventricles. TTE is also fundamental to distinguish heart failure with preserved ejection fraction ( $\mathrm{HFpEF}$ ) from heart failure with reduced ejection fraction $(\mathrm{HFrEF})$, which differ in both prognosis and treatment [18].

It is also important to prescribe blood tests, such as [19]:

- full blood count: to rule out anemia that may precipitate HF or offer an alternative explanation for breathlessness and to exclude neutrophilia that may suggest an infective cause of breathlessness;
Figure 1. Diagnostic algorithm for heart failure. Modified from [8]

$\mathrm{BNP}=\mathrm{B}$-type natriuretic peptide;

$\mathrm{CAD}=$ coronary artery disease;

$\mathrm{ECG}=$ electrocardiogram $\mathrm{HF}=$ heart failure;

MI=myocardial infarction; NT-proBNP=N-terminal pro-B type natriuretic peptide

${ }^{a}$ Patient reporting symptoms typical of $\mathrm{HF}$

${ }^{\mathrm{b}}$ Normal ventricular and atrial volumes and function

'Consider other causes of elevated natriuretic peptides 


\begin{tabular}{|c|c|}
\hline Parameter & Detected value \\
\hline Heart rate & 62 bpm \\
\hline$P Q$ & $0.20 \mathrm{~s}$ \\
\hline QRS axis & $-30^{\circ}$ \\
\hline QRS & $0.18 \mathrm{~s}$ \\
\hline
\end{tabular}

Table I. Electrocardiography findings

- thyroid status: hypothyroidism and hyperthyroidism are important risk factors to develop HF and they need an appropriate treatment;

- liver function tests: to reveal hepatic congestion resulting from a right $\mathrm{HF}$ and because hypoalbuminemia may result in fluid retention and consequent peripheral edema;

- renal function tests: renal failure may result in fluid overload, and a baseline renal function is crucial for treating HF with diuretics and angiotensin-converting enzyme (ACE) inhibitors, that may worsen renal function and cause electrolyte disequilibrium;

- lipid profile and glycated hemoglobin: to evaluate cardiovascular risk.

\section{How should this condition be managed? (The medical therapy)}

While waiting for the results of the required clinical tests, the GP prescribed the immediate discontinuation of NSAIDs, the beginning of diuretic therapy with the addition of furosemide $(50 \mathrm{mg} /$ day by mouth), and the revaluation of antihypertensive therapy with a dose escalation of ramipril to $7.5 \mathrm{mg} /$ day.

First of all, on the basis of the Hippocratic principle primum non nocere, it is essential to avoid all drug treatments that might exacerbate HF (e.g. NSAIDs, the probable cause of heart failure precipitation in this case). It is demonstrated that high doses of commonly used NSAIDs could double the risk of developing a new heart failure [20] or easily induce an exacerbation of a pre-existing one with an increase in hospitalizations [21].

Diuretics are useful to decrease the signs and symptoms of congestion in patients with HF [22], even if their effects on morbidity and mortality have not been analyzed in randomized controlled trials [8]. The aim of diuretic therapy is to reach and maintain euvolemia with the lowest achievable dose.
The dose of the diuretic must be modified according to the individual necessities over time [11].

The beneficial effects of ACE inhibitors in heart failure include improvements in survival chance, rate of hospitalization, symptoms, cardiac performance, neurohormonal levels, and reverse remodeling [23]. It's critical to increase (like the GP did in this case) $\mathrm{ACE}$ inhibitor (for example, doubling the dose every 2-4 weeks) until the target dose is achieved or side effects appear. Renal function tests should be performed within 1-2 weeks from each dose increment to check that blood creatinine levels and estimated glomerular filtration rate are stable and hyperkalemia is absent [11].

Angiotensin receptor blockers (ARBs) are recommended only as an alternative in patients intolerant to $\mathrm{ACE}$ inhibitors because of severe cough or angioedema [24].

Beta-blockers (BBs) have a protective effect on the heart, exerted through the inhibition of adrenergic system with inotropic and negative chronotropic effects. The use of BBs results in a reduction in mortality, morbidity, and hospitalization for HF exacerbation and improves the severity of symptoms [25].The treatment with BBs should be initiated in stable patients and gradually up-titrated to the maximum tolerated dose, while, in case of exacerbation of chronic $\mathrm{HF}$, it must be reduced or discontinued or not started (like in this case) [26]. Furthermore, the administration of BBs, especially cardioselective ones, in patients with COPD is safe and the presence of a COPD is no longer a contraindication to the use of BBs in a patient with HF [27].

Recently, a new therapeutic class of drugs called angiotensin receptor neprilysin inhibitors (ARNI) has been developed. They act on the renin-angiotensin-aldosterone system (RAAS) and the neutral endopeptidase system. Sacubitril/valsartan, the first medication of this new class, is recommended as a replacement for an ACE inhibitors to further reduce the risk of death and HF hospitalization in patients with $\mathrm{HFrEF}$ who remain symptomatic despite optimal treatment with $\mathrm{BBs}, \mathrm{ACE}$ inhibitors, and mineralocorticoid receptor antagonists [28].

All the foregoing considerations are valid only for patients with HFrEF. Conversely, no therapy significantly improves survival or prevents hospitalizations in patients affected by heart failure with normal ejection fraction. The objective in these patients is to relieve symptoms with diuretics and treat hypertension and other comorbidities [29]. 


\section{Outcomes}

The ECG revealed a sinus rhythm and a left bundle branch block (LBBB) in addition to the findings reported in Table I. A severe cardiomegaly was apparent at the chest radiography, which revealed also bibasilar pulmonary edema with bilateral small pleural effusions. Blood tests highlighted 4 parameters outside the normal range (Table II).

Transthoracic echocardiogram (TTE) was not yet run.

\section{Does this condition require hospitalization? \\ (The hospitalization)}

On the basis of the above-mentioned data, that confirmed the initial suspicion of NSAIDsinduced heart failure and showed an acute renal failure and an acute anemia (both not previously present), the GP decided to hospitalize the patient.

$\mathrm{HF}$ is the most common reason of hospitalization in patients over 65 years of age [30]. Unfortunately, evidence from the literature to guide the decision about the hospitalization of a HF patient is scarce [31]. Therefore, patient's hospitalization depends on numerous subjective factors, including both the severity of underlying condition and comorbidities. In this case, the decision was related to the need to understand the underlying etiology of a first episode of $\mathrm{HF}$ in a complex patient with multicomorbidity (COPD, acute renal failure, and anemia). Moreover, the concomitant presence of severe cardiomegaly and LBBB (already present in previous ECGs, but the patient had never wanted to undergo more examinations) made the GP suspect the presence of a HFrEF, that must be confirmed by the execution of a TTE, and eventually treated with a cardiac resynchronization therapy implantation [32].

Furthermore, the hospitalization is necessary to perform intravenous diuretic therapy with a strict monitoring of hydro-balance and kidney function, in light of the finding of concomitant acute renal failure. It is also important to understand the etiology of anemia and treat it (the hypothesis of a gastrointestinal bleeding connected to the use of NSAIDs is plausible): anemia is another indicator of the grade of severity of this clinical

\begin{tabular}{|c|c|c|}
\hline Parameter & Detected value & Normal range \\
\hline Hemoglobin $(\mathrm{g} / \mathrm{d})$ ) & 8.1 & $11.5-15.5$ \\
\hline Mean Corpuscular Volume (fl) & 78 & $80-97$ \\
\hline Creatinine $(\mathrm{mg} / \mathrm{dl})$ & 2.4 & $0.6-1.5$ \\
\hline Brain Natriuretic Peptide (pg/ml) & 280 & $<35$ \\
\hline
\end{tabular}

picture since it is an independent factor of in-hospital mortality risk in patients with

Table II. Blood test results

\section{How should this condition be followed up? (The follow up)}

After hospital discharge, it was time to organize a multidisciplinary team management, through periodic medical examinations by the GP and the cardiology outpatient clinic, to follow-up and monitor patient's condition.

One of the key problems of healthcare system with heart failure patients is the very high rate of re-hospitalization. Up to $25 \%$ of patients hospitalized with HF are readmitted within 30 days [34] and a re-hospitalization is one of the strongest prognostic predictors for augmented mortality too [35].

The goal of HF management is to organize a seam-less system of care that embraces both the hospital and the community throughout the healthcare process. A close integration between GPs, hospital and territory cardiologists, specialist nurses, social workers, etc. can reduce HF hospitalization and mortality in patients discharged from the hospital [36] and decrease medical costs [37]. Multidisciplinary team management is also essential for the full implementation of non-pharmacological therapy through weight monitoring, avoiding salty foods, and harmful drugs (such as NSAIDs in this case), fluid intake, and possible flexible use of diuretic therapy [38]. An important task of the GP in the HF post discharge is to avoid medication non-adherence, which is a common precipitant of re-hospitalization and is associated with poor outcomes [39].

\section{CONCLUSION}

Heart failure is a very difficult disease to frame and diagnose, and unfortunately signs and symptoms are highly nonspecific. General practitioners may have unique insight 
Keypoints

- Clinical history and physical examination may indicate the presence of heart failure

- Laboratory tests (e.g., natriuretic peptides) and instrumental exams allow physicians to diagnose and manage patients with heart failure in everyday medical practice

- NSAID intake may act as precipitating factor for HF

- The organization of a multidisciplinary intervention may be a very useful resource, resulting in the reduction in the rate of hospital admissions and mortality for $\mathrm{HF}$

into the patient's medical history and some laboratory tests and instrumental exams can help physicians to diagnose and manage heart failure. Natriuretic peptides can play an important role in this setting and may eventually become part of the standard package of tests both in the acute phase and during the follow-up. The organization of a multidisciplinary intervention, focused on both the patient and the caregiver, is of no less importance and it results in the reduction in hospital admission rate and mortality.

\section{REFERENCES}

1. McMurray JJ, Adamopoulos S, Anker SD, et al. ESC guidelines for the diagnosis and treatment of acute and chronic heart failure 2012: the Task Force for the diagnosis and treatment of acute and chronic heart failure 2012 of the European Society of Cardiology. Developed in collaboration with the Heart Failure Association (HFA) of the ESC (HFA). Eur Heart J 2012; 33: 1787-847; https://doi.org/10.1093/eurheartj/ehs104

2. Mosterd A, Hoes A. Clinical Epidemiology of heart failure. Heart 2007; 93: 1137-46; https:// doi.org/10.1136/hrt.2003.025270

3. Fuat A, Hungin AP, Murphy JJ. Barriers to accurate diagnosis and effective management of heart failure in primary care: qualitative study. BMJ 2003; 326: 196; https://doi.org/10.1136/ bmj.326.7382.196

4. Loehr LR, Rosamond WD, Chang PP, et al. Heart failure incidence and survival (from the Atherosclerosis Risk in Communities study). Am J Cardiol 2008; 101: 1016-22; https://doi. org/10.1016/j.amjcard.2007.11.061

5. Gheorghiade M, Bonow RO. Chronic heart failure in the United States: a manifestation of coronary artery disease. Circulation 1998; 97: 282-9; https://doi.org/10.1161/01.CIR.97.3.282

6. He J, Ogden LG, Bazzano LA, et al. Risk factors for congestive heart failure in US men and women: NHANES I epidemiologic follow-up study. Arch Intern Med 2001; 161: 996-1002; https://doi.org/10.1001/archinte.161.7.996

7. Agusti A, Decramer M, Celli BR, et al. Global strategy for the diagnosis, management, and prevention of chronic obstructive pulmonary disease. 2017 Report. (C) Global Initiative for Chronic Obstructive Pulmonary Disease. Available at http://goldcopd.org/gold-2017-globalstrategy-diagnosis-management-prevention-copd/ (last accessed July 2017)

8. Ponikowski P, Voors AA, Anker SD, et al. Authors/Task Force Members, Document Reviewers. 2016 ESC Guidelines for the diagnosis and treatment of acute and chronic heart failure: The Task Force for the diagnosis and treatment of acute and chronic heart failure of the European Society of Cardiology (ESC), Developed with the special contribution of the Heart Failure Association (HFA) of the ESC. Eur J Heart Fail 2016; 18: 891-975; https://doi.org/10.1002/ ejhf.592

9. Jessup M, Brozena S. Heart failure. NEnglJMed 2003; 348: 2007-18; https://doi.org/10.1056/ NEJMra021498; https://doi.org/10.1056/NEJMe030030

10. Mant J, Doust J, Roalfe A, et al. Systematic review and individual patient data meta-analysis of diagnosis of heart failure with modelling of implications of different diagnostic strategies in primary care. Health Technol Assess 2009; 13: 1-207; https://doi.org/10.3310/hta13320

11. Williams RP, Oakeshott P. Diagnosis and management of chronic heart failure. BMJ 2014; 348: 1429; https://doi.org/10.1136/bmj.g1429

12. Omland T, Hagve TA. Natriuretic peptides: physiologic and analytic considerations. Heart Fail Clin 2009; 5: 471-87; https://doi.org/10.1016/j.hfc.2009.04.005 
13. Maisel A, Mueller C,Adams K, et al. State of the art: using natriuretic peptide levels in clinical practice. Eur J Heart Fail 2008; 10: 824-39; https://doi.org/10.1016/j.ejheart.2008.07.014

14. Zaphiriou A, Robb S, Murray-Thomas T, et al. The diagnostic accuracy of plasma BNP and NTproBNP in patients referred from primary care with suspected heart failure: results of the UK natriuretic peptide study. Eur J Heart Fail 2005; 7: 537-41; https://doi.org/10.1016/j. ejheart.2005.01.022

15. Lainchbury JG, Troughton RW, Strangman KM, et al. NTerminal Pro-B-Type Natriuretic Peptide-Guided Treatment for Chronic Heart Failure: results from the BATTLESCARRED (NT-proBNP-Assisted Treatment to Lessen Serial Cardiac Readmissions and Death) trial. $J$ Am Coll Cardiol 2009; 55: 53-60; https://doi.org/10.1016/j.jacc.2009.02.095

16. Khunti K, Squire I, Abrams KR, et al. Accuracy of a 12-lead electrocardiogram in screening patients with suspected heart failure for open access echocardiography: a systematic review and meta-analysis. Eur J Heart Fail 2004; 6: 571-6; https://doi.org/10.1016/j.ejheart.2004.03.013

17. Thomas JT, Kelly RF, Thomas SJ, et al. Utility of history, physical examination, electrocardiogram, and chest radiograph for differentiating normal from decreased systolic function in patients with heart failure. Am J Med 2002; 112: 437-45; https://doi.org/10.1016/S0002-9343(02)01048-3

18. McMurray JV. Systolic Heart Failure. NEnglJMed 2010; 362:228-38; https://doi.org/10.1056/ NEJMcp0909392

19. Kotecha T, Fox K. Investigating suspected heart failure. BMJ 2013; 346: 2442; https://doi. org/10.1136/bmj.f2442

20. Bhala N, Emberson J, Mehri A, et al. Coxib and traditional NSAID Trialists' Collaboration, Vascular and upper gastrointestinal effects of non-steroidal anti-inflammatory drugs: metaanalyses of individual participant data from randomised trials. Lancet 2013;382: 769-79; https:// doi.org/10.1016/S0140-6736(13)60900-9

21. Ungprasert P, Patompong N, Kittanamongkolchai W. Non-steroidal anti-inflammatory drugs and risk of heart failure exacerbation: A systematic review and meta-analysis. Eur J Intern Med 2015; 26: 685-90; https://doi.org/10.1016/j.ejim.2015.03.008; https://doi.org/10.1016/j. ejim.2015.09.012

22. Faris R, Flather M, Purcell $\mathrm{H}$, et al. Current evidence supporting the role of diuretics in heart failure: a meta analysis of randomised controlled trials. Int J Cardiol 2002; 82: 149-58; https:// doi.org/10.1016/S0167-5273(01)00600-3

23. Garg R, Yusuf S. Overview of randomized trials of angiotensin-converting enzyme inhibitors on mortality and morbidity in patients with heart failure. JAMA 1995; 273: 1450-6; https:// doi.org/10.1001/jama.1995.03520420066040; https://doi.org/10.1001/jama.273.18.1450

24. Granger CB, McMurray JJV, Yusuf S, et al. Effects of candesartan in patients with chronic heart failure and reduced left-ventricular systolic function intolerant to angiotensin-convertingenzyme inhibitors: the CHARM-Alternative trial. Lancet 2003; 362: 772-6; https://doi. org/10.1016/S0140-6736(03)14284-5

25. CIBIS-II Investigators and Committees. The Cardiac Insufficiency Bisoprolol Study II (CIBISII): a randomised trial. Lancet 1999; 353: 9-13; https://doi.org/10.1016/S0140-6736(98)11181-9

26. Jondeau G, Neuder Y, Eicher JC, et al. B-CONVINCED: Beta-blocker CONtinuation Vs INterruption in patients with Congestive heart failure hospitalizED for a decompensation episode. Eur Heart J 2009; 30: 2186-92; https://doi.org/10.1093/eurheartj/ehp323

27. Campo G, Pavasini R, Biscaglia S, et al. Overview of the pharmacological challenges facing physicians in the management of patients with concomitant cardiovascular disease and chronic obstructive pulmonary disease. Eur Heart J Cardiovasc Pharmacother 2015; 1: 205-11; https:// doi.org/10.1093/ehjcvp/pvv019

28. McMurray JJV, Packer M, Desai AS, et al. Angiotensin-neprilysin inhibition versus enalapril in heart failure. NEnglJ Med 2014; 371: 993-1004; https://doi.org/10.1056/NEJMoa1409077

29. Rutten FH, Clark AL, Hoes AW. How big a problem is heart failure with a normal ejection fraction? BMJ 2016; 352: i1706; https://doi.org/10.1136/bmj.i1706

30. Jencks SF, Williams MV, Coleman EA. Rehospitalizations among patients in the Medicare fee-for-service program. $N$ Engl J Med 2009; 360: 1418-28; https://doi.org/10.1056/ NEJMsa0803563

31. Miró Ò, Peacock FW, McMurray JJ, et al. European Society of Cardiology - Acute Cardiovascular Care Association position paper on safe discharge of acute heart failure patients from the emergency department. Eur Heart J Acute Cardiovasc Care 2017; 6: 311-20; https:// doi.org/10.1177/2048872616633853

32. Cleland JG,Abraham WT, Linde C, et al. An individual patient meta-analysis of five randomized trials assessing the effects of cardiac resynchronization therapy on morbidity and mortality in 
patients with symptomatic heart failure. Eur Heart J2013; 34: 3547-56; https://doi.org/10.1093/ eurheartj/eht290

33. Kajimoto K, Sato N, Takano T; investigators of the Acute Decompensated Heart Failure Syndromes (ATTEND) registry. Association of anemia and renal dysfunction with in-hospital mortality among patients hospitalized for acute heart failure syndromes with preserved or reduced ejection fraction. Eur Heart J Acute Cardiovasc Care 2016; 5: 89-99; https://doi. org/10.1177/2048872615593387

34. Dharmarajan K, Hsieh AF, Lin Z, et al. Diagnoses and timing of 30-day readmissions after hospitalization for heart failure, acute myocardial infarction, or pneumonia.JAMA 2013; 309: 355-63; https://doi.org/10.1001/jama.2012.216476

35. Gheorghiade M, Vaduganathan M, Fonarow GC, et al. Rehospitalization for heart failure: problems and perspectives. J Am Coll Cardiol 2013; 61: 391-403; https://doi.org/10.1016/j. jacc.2012.09.038

36. Feltner $\mathrm{C}$, Jones $\mathrm{CD}$, Cenè $\mathrm{CW}$, et al. Transitional care interventions to prevent readmissions for persons with heart failure: a systematic review and meta-analysis. Ann Intern Med 2014; 160: 774-84; https://doi.org/10.7326/M14-0083

37. Chinaglia A, Gaschino G, Asteggiano R, et al.Impact of a nurse-based heart failure management program on hospitalization rate, functional status, quality of life, and medical cost. Ital Heart J 2002; 3: 532-8

38. Lainscak M, Blue L, Clark AL, et al. Self-care management of heart failure: practical recommendations from the Patient Care Committee of the Heart Failure Association of the European Society of Cardiology. Eur J Heart Fail 2011; 13: 115-26; https://doi.org/10.1093/ eurjhf/hfq219

39. Sueta CA, Rodgers JE, Chang PP, et al. Medication adherence based on part D claims for patients with heart failure after hospitalization (from the Atherosclerosis Risk in Communities Study).Am J Cardiol 2015; 116: 413-9; https://doi.org/10.1016/j.amjcard.2015.04.058 